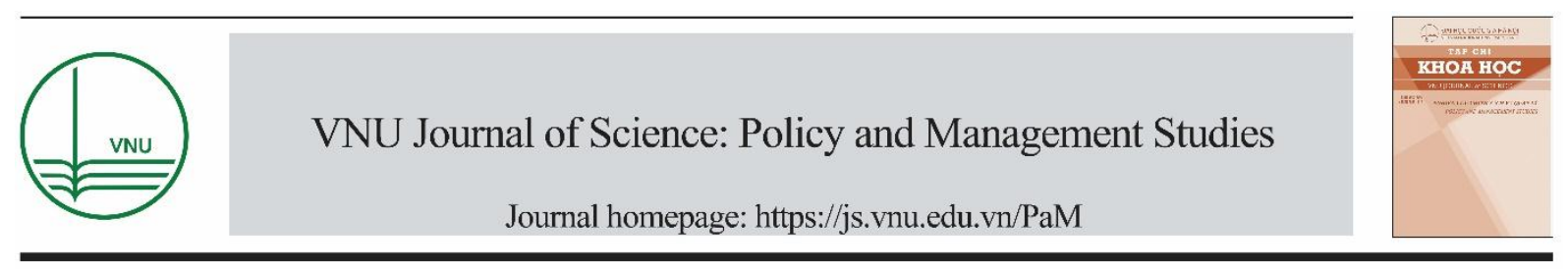

Original Article

\title{
Social Policy of Science Viewed from the Aspect of Sociology - Research and some Discussions
}

\author{
Tran Van Huan, Nguyen Huu Hoang* \\ Academy Politics of Region II, 99 Man Thien, Hiep Phu, 9 District, Hochiminh City
}

Received 11 July 2019

Revised 03 March 2020; Accepted 04 March 2020

\begin{abstract}
Sociology and social policy of science are one of the new sciences but full of potiential for development in Vietnam. This paper combines more methodologies to analyze the basic relationships of them by some aspects in practise. The consequences bring more new think, to be looked down on or even denied about relating between two these sciences.

Keywords: Social policy of science, sociology, Vietnam.
\end{abstract}

\footnotetext{
* Corresponding author.

E-mail address: huuhoang.hcma2@gmail.com

_https://doi.org/10.25073/2588-1116/vnupam.4188
} 


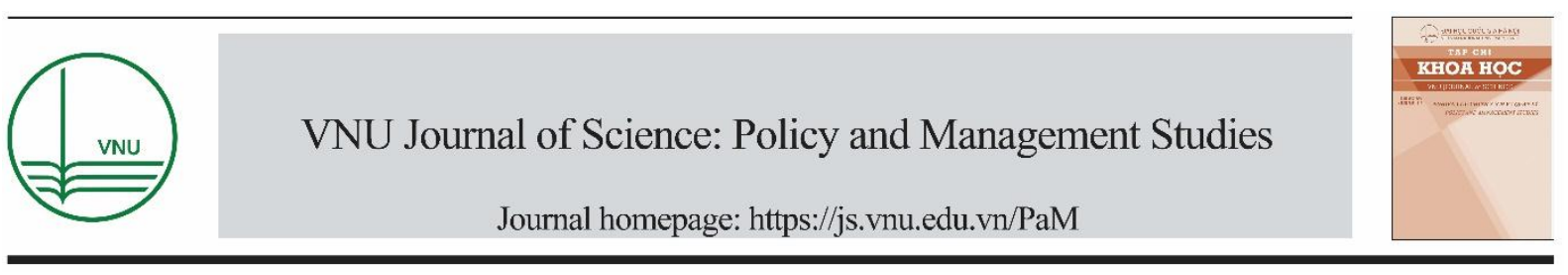

\title{
Khoa học chính sách xã hội nhìn từ lăng kính xã hội học - Nghiên cứu và một vài luận bàn
}

\author{
Trần Văn Huấn, Nguyễn Hữu Hoàng* \\ Học viện Chính trị khu vưc II, 99 Man Thiện, Hiệp Phú, Quận 9, TP. Hồ Chí Minh \\ Nhận ngày 11 tháng 7 năm 2019 \\ Chỉnh sửa ngày 17 tháng 3 năm 2020; Chấp nhận đăng ngày 20 tháng 3 năm 2020
}

\begin{abstract}
Tóm tắt: Xã hội học và khoa học chính sách xã hội là một trong số ít những ngành khoa học non trẻ nhưng lại đầy triển vọng phát triển ở Việt Nam. Bài viết sử dụng kết hợp đa phương pháp nghiên cứu nhằm luận bàn về mối quan hệ căn bản, tự thân và chặt chẽ giữa khoa học chính sách xã hội và xã hội học thông qua một số phương diện biểu hiện trong thực tiễn vận hành, phát triển của nó. Kết quả nghiên cứu mang lại những nhận thức mới mẻ, gián tiếp bác bỏ những quan niệm hoặc xem nhẹ, hoặc phủ nhận về mối quan hệ giữa hai ngành khoa học này ở nước ta.
\end{abstract}

Tù khoá: Khoa học chính sách xã hội, xã hội học, Việt Nam.

\section{Mở đầu}

So với các ngành khoa học xã hội khác như sử học, văn học, triết học, tôn giáo học, chính trị học, ... xã hội học và khoa học chính sách xã hội vần là những ngành khoa học có tuổi đời khá trẻ. Ở Việt Nam, lịch sử phát triển của hai ngành khoa học này có bề dày lịch sử còn khá khiêm tốn. Nếu tính kể từ khi xã hội học được chính thức công nhận là một ngành khoa học thực thụ trên phạm vi toàn thế giới gắn liền với tên tuổi của Auguste Comte - ông tổ của ngành xã hội học vào năm 1838 đến nay đã 181 năm $[1$, tr.27]. Lịch sử hình thành và phát triển xã hội học ở nước ta thậm chí còn muộn hơn so với xã hội học thế giới khoảng 1 thế kỷ [2, tr.01]. Là một dạng của chính sách công, chính sách xã hội chỉ mới được nghiên cứu ở tầm khoa học trên thế giới từ nửa cuối thế kỷ XX, sau Thế chiến lần thứ II, đặc biệt, được đánh dấu vào thời điểm học giả Harold D. Lasswell công bố tác phẩm "The Policy Orientation, The Policy Science: Recent Development in Scope and Method" [3] xuất bản năm 1951. Riêng ở Việt Nam, thuật ngữ chính sách xã hội chỉ mới xuất hiện vào cuối thập niên 70 đến đầu thập niên 80 của thế kỷ XX ở dạng thông tin khoa học xã hội và được chính thức được đưa vào Văn kiện Đại hội Đảng toàn quốc lần thứ VI (12/1986) làm thành tiêu đề cho một phần riêng biệt. Tuy có lịch sử tương đối ngắn song từ khi ra đời đến nay, xã hội học và chính sách xã hội (nếu nhìn ở góc độ ngành khoa học) ở nước ta đã có bước phát triển nhanh chóng, không chỉ thuần tuý là khoa học lý luận mà còn là ngành khoa học ứng dụng, đóng góp tích cực vào sự nghiệp đổi mới và phát triển đất nước, trở thành công cụ điều hành quản lý phát triển xã hội hữu hiệu, quan trọng. 
Xã hội học và khoa học chính sách xã hội có nhiều điểm tương đồng về lịch sử hình thành, phát triển, về đối tượng nghiên cứu, phương pháp tiếp cận hay thậm chí là vai trò và vị trí là công cự quan trọng bậc nhất, nền tảng, có tính định hướng, dẫn dắt cho các công cụ khác trong lãnh đạo, quản lý xã hội... Ngoài ra, thực tiễn vận động và phát triển của chúng sau hơn 30 năm Đổi mới đất nước cho thấy đây là hai ngành khoa học có mối quan hệ chặt chẽ, tương hỗ một cách mật thiết; vừa là đối tượng song cũng là mục tiêu, động lực nghiên cứu để hoàn thiện lẫn nhau. Như Anthony Giddens, một giáo sư xã hội học nổi tiếng tại Đại học Cambridge (Vương quốc Anh) từng khẳng định: "Có một sự tham gia sâu sắc của xã hội học vào việc hình thành những chính sách xã hội hoặc cải cách thực tiễn" [4, pp.4446]. Ở một phát biểu khác, nhà xã hội học người Nga V. Z. Rôgôvin cùng Iu. E. Vôncốp thì cho rằng: "Với tính cách là một môn khoa học, chính sách xã hội là một lĩnh vực tri thức xã hội học, nghiên cứu hệ thống về các quá trình xã hội quyết định hoạt động sống của con người trong xã hội, xét theo khả năng tác động quản lý đến các quá trình đó" [5, tr.10-11], là "một trong những khía cạnh của xã hội học Mác - Lênin" [5].

Tuy vậy, phải thẳng thắn nhìn nhận, dù bước đầu được thừa nhận, có đóng góp đáng kể cả ở tầm lý luận, học thuyết và thực tiễn quản trị quốc gia song nhận thức về mối quan hệ hỗ trợ một cách biện chứng, về sự gắn bó dưới góc nhìn khoa học lẫn thực tiễn khách quan giữa hai ngành khoa học này vẫn còn nhiều ý kiển chưa thống nhất, thậm chí trái chiều. Điều này dễ hiểu bởi lẽ một phần trong nhiều tài liệu, giáo trình về xã hội học và khoa học chính sách nói chung hoặc chưa hoặc còn mờ nhạt khi đề cập đến mối quan hệ giữa chúng hoặc hiếm đề cập khi tiếp cận ngành khoa học này ở giác độ của ngành khoa học kia hoặc ngược lại $[6, \operatorname{tr} .5]$. Do vậy cần có sự nghiên cứu và bổ khuyết nhanh chóng.

Thông qua nghiên cứu này, đặc biệt từ mối quan hệ tự thân của xã hội học và khoa học chính sách xã hội được phân tích trên một số phương diện cơ bản, bài viết góp phần đem lại cách nhìn nhận đầy đủ, sâu sắc hơn về sự kết nối mang tính nguyên tắc, tất yếu và cần thiết giữa hai ngành khoa học mới mẻ này. Từ đó khẳng định, đấy là nền tảng để xây dựng hệ thống công cụ - chính sách xã hội đáp ứng kỳ vọng là công cụ vĩ mô quan trọng hàng đầu, hiện đại, thực chứng, vừa có tính khoa học lẫn thực tiễn, có tính định hướng cho các công cụ quản lý phát triển xã hội khác ở Việt Nam.

\section{Phương pháp luận nghiên cứu}

Từ điển Triết học do M. M. Rodentan (1986) [7] chủ biên cho rằng phương pháp luận có 2 nghĩa: 1 ). học thuyết về phương pháp và 2 ). các phương pháp trong nghiên cứu. Điều này cũng tương tự như nhận định của John Scott và Gordon Marshall (2009) [8]. Để nhìn nhận, luận giải thấu đấu về mối quan hệ giữa khoa học chính sách xã hội qua góc nhìn, tiếp cận của xã hội học, tác giả sử dụng phương pháp luận của chủ nghĩa duy vật biện chứng và duy vật lịch sử làm cơ sở phương pháp luận.

Ngoài ra, bài viết chú ý sử dụng kết hợp đa phương pháp nghiên cứu, có tính bổ trợ nhau và thường được áp dụng trong lĩnh vực khoa học xã hội - nhân văn như phương pháp lý thuyết, phân tích - tổng hợp, logic cho đến phương pháp lịch sử, diễn dịch, hay quy nạp,... Trên cơ sở tổng kết lý luận một cách có chắc lọc, dựa trên quan điểm của cá nhà nghiên cứu kinh điển và tư duy cá nhân, các lý thuyết về xã hội học, khoa học chính sách xã hội vốn vô cùng phong phú, phức tạp được khái quát hoá và khu biệt một cách có hệ thống, phù hợp với hướng tiếp cận của bài viết nhưng cũng không lệch xa so với nhận thức chung của giới nghiên cứu. Phương pháp logic và lịch sử được thể hiện rất rõ nét, chủ yếu chỉ ra, lí giải một cách thuyết phục, rõ ràng, rành mạch về mối quan hệ biện chứng nhưng ít được quan tâm giữa xã hội học và chính sách xã hội cả góc nhìn thực tế và nghiên cứu trong chiều dài lịch sử hình thành, phát triển của 2 ngành khoa học non trẻ này, gắn với bối cảnh Việt Nam. 


\section{Khoa học chính sách xã hội từ cách tiếp cận xã hội học thông qua một số phương diện cơ bản}

\subsection{Nhận thức ban đầu về nội hàm xã hội học và khoa học chính sách xã hội}

Để có thể luận bàn sâu sắc hơn về khoa học chính sách xã hội dưới góc nhìn xã hội học nhất thiết phải nhận thức thống nhất về nội hàm của các thuật ngữ này (ít nhất là trong bài viết này).

Về xã họi hoc: Trong hành trình phát triển của mình, việc nhận thức một cách hoàn bị thế nào là xã hội học ở thế giới và Việt Nam chưa hẳn là việc đã "xong xuôi”" nhưng đến nay, các học giả tạm thống nhất và đồng tình với quan niệm: đó là khoa học nghiên cứu về các quy luật nảy sinh, biến đổi, phát triển mối quan hệ giữa con người với con người, giữa con người với xã hội trên các mặt của đời sống xã hội như kinh tế, văn hoá, chính trị, tư tưởng [9, tr.283], [1, tr.27],... Như vậy, phải khẳng định, đối tượng nghiên cứu của xã hội học gắn liền với sự vận động và phát triển của đời sống xã hội - mà ở đó, các quy luật trong vận hành quan hệ của xã hội người cũng là đối tượng được chính sách xã hội quan tâm nghiên cứu.

Về khoa học chính sách xã hội: Ở Việt Nam, chính sách xã hội dựa trên kinh nghiệm đã có từ lâu và song chính sách xã hội khoa học vẫn là ngành khoa học mới mẻ. Xét ở giác độ chính sách xã hội dựa trên kinh nghiệm, đấy là một bộ phận của chính sách công với trọng tâm là đưa ra các giải pháp, phương pháp tổng thể nhằm giải quyết các vấn đề của xã hội, hướng đến xây dựng xã hội thịnh vượng, phát triển. Ở giác độ là khoa học chính sách xã hội, trong bài viết này, thông qua phương pháp tổng tích hợp về các tri thức chính sách xã hội, khoa học chính sách và muc tiêu nghiên cứu, tác giả đề xuất định nghĩa thuật ngữ khoa hoc chính sách xã hộ $i$ đấy chính là một ngành khoa học của chính sách có đối tượng nghiên cứu là cách thức chính sách xã hội vận hành, giải quyết các vấn đề xã hội dưới tác động của chính sách ấy, đồng thời, cung cấp tri thức khoa học có tính hệ thống cho các nhà làm chính sách xã hội, những ai quan tâm đến chính sách xã hội góp phần phát triển con người và phát triển xã hội [10, tr.40-41].

Rõ ràng, các phát biểu nêu trên tuy là suy ngẫm, đúc kết của cá nhân trên cơ sở tìm tòi, kế thừa hạt nhân hợp lí của các học giả đi trước song cũng chứng minh cho sự phong phú, đa dạng và muôn vẻ trong quá trình hướng đến việc nhận thức đến tận cùng bản chất thực sự của khoa học chính sách xã hội và xã hội học và các vấn đề liên quan giữa chúng vốn còn hiếm hoi trong giới nghiên cứu ở nước ta trong hai lĩnh vực này.

Nghiên cứu về mối quan hệ khoa học chính sách xã hội từ cách tiếp cận và qua lăng kính của xã hội học trong bài viết này được thể hiện ở 04 chiều cạnh chủ yếu được thể hiện ở khung phân tích sau đây:

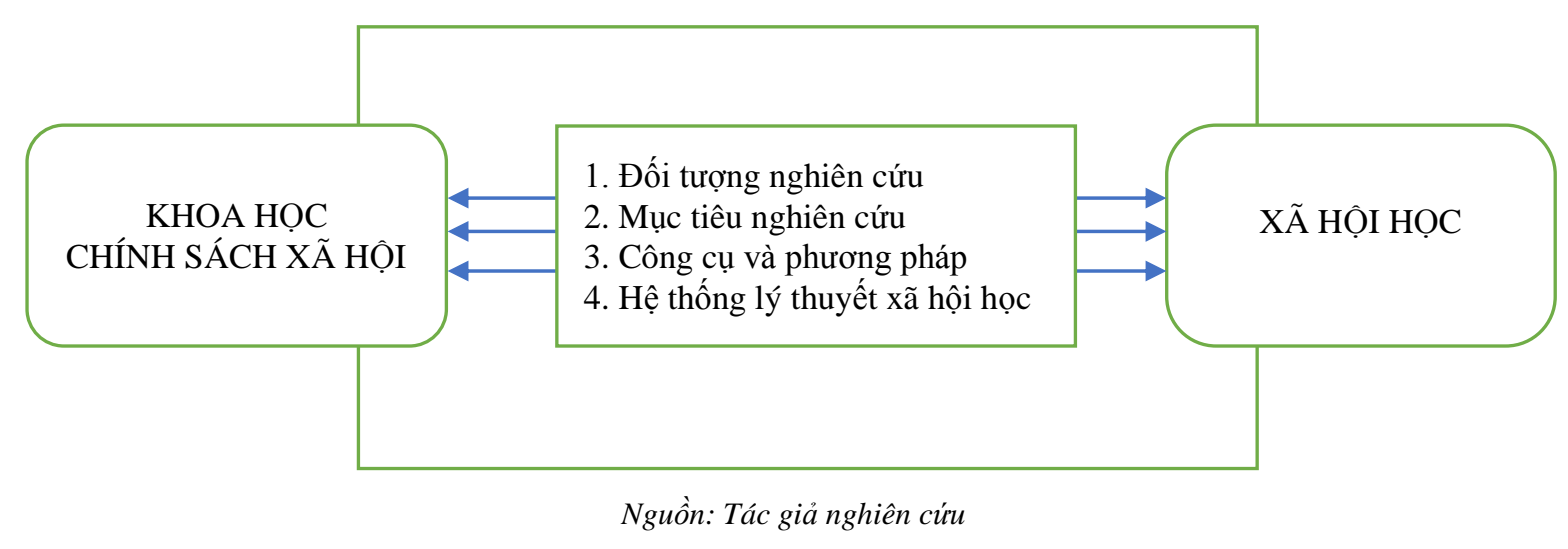




\subsection{Nghiên cứu khoa học chính sách xã hội tù góc nhìn xã hội học qua các phuoong diện biểu hiện cơ bản}

Một là, thông qua phương diện là "đối tuợng nghiên cưu". Được công nhận là một ngành khoa học liên ngành, xã hội học và khoa học chính sách công có đối tượng nghiên cứu khá gần gũi và hữu cơ với nhau. Xã hôi học tập trung nghiên cứu, tìm kiếm các quy luật phổ quát nhất, khái quát thành các lý thuyết xã hội học về các vấn đề nảy sinh trong mối quan hệ giữa người với người, giữa con người với xã hội trên các phương diện của đời sống xã hội thông qua hệ thống phương pháp thực nghiệm.Trong khi đó, khoa học chính sách xã hội có sự quan tâm đặc biệt đến các quy luật, lý thuyết đã xã hội được nghiên cứu và khái quát. Bởi lẽ, với ngành khoa học này - đối tượng nghiên cứu của xã hội học đã trở thành "vấn đề chính sách xã hội" mà khoa học chính sách xã hội cần đào sâu nghiên cứu và thực tiễn chính sách xã hội phải quan tâm, cân nhắc và có phương thức giải quyết ở tầm chính sách. Chẳng hạn, kết quả nghiên cứu của xã hội học về "cấu trúc xã hội", "phân tầng xã hội", "biến đồi xã hội" ở các chiều cạnh khác nhau (như "bình đẳng giới", "dân số", "di dân", "nghèo đói") ... luôn là các vấn đề quan tâm trung tâm không chỉ của chính sách xã hội xét ở mức kinh nghiệm mà còn ở chính sách xã hội khoa học để hình thành cách thức, hoàn thiện tri thức khoa học về ngành khoa học này, soi rọi, dẫn chiếu và giúp các nhà lãnh đạo, quản lý giải quyết thực tiễn mà xã hội học đã đặt ra cho khoa học chính sách xã hội nghiên cứu. Như vậy, sợi dây gắn kết giữa chúng chính là kết quả nghiên cứu của xã hội học là dữ liệu đầu vào cần thiết cho việc khởi động quá trình chính sách xã hội, là sự bổ khuyết trong quá trình nghiên cứu của khoa học chính sách công; đồng thời, nghiên cứu chính sách xã hội có thể được xem là một nhiệm vụ của xã hội học, là một chuyên ngành của xã hội học ứng dụng [11, tr.45].

Tuy nhiên, nói như vậy, không có nghĩa là phủ định tính năng động, sáng tạo nắm bắt vấn đề chính sách xã hội của khoa học chính sách xã hội. Bởi lẽ, khoa học chính sách xã hội là khoa học chính sách liên ngành với nhiều ngành khoa học khác như chính trị học, quản lý học, tâm lí học,,.. song với xã hội học, giữa hai ngành khoa học này có sự gần gũi đặc biệt. Trong chừng mực nhất định, kết quả nghiên cứu trong giới khoa học chính sách xã hội và thực tiễn đúc kết được từ quá trình vận động của chính sách xã hội cũng tạo ra những cơ sở xã hội mới cho sự phát triển của xã hội học. Xã hội học không thể chứng tỏ được chứng năng xã hội của mình nếu nó không được tiếp nối bằng các nghiên cứu của khoa học chính sách xã hội, nói cách khác, nghiên cứu chính sách xã hội trở thành mục tiêu và yêu cầu quan trọng nhất của các công trình nghiên cứu xã hội học [11, tr.45].

Hai là, ở phuoong diện muc tiêu và giải quyết vấn đề có tính triết học trong nghiên cứu của hai ngành khoa hoc. Xã hội học và khoa học chính sách xã hội đều là khoa học "vị nhân sinh", tức là khoa học có tính ứng dụng cao vì con người, vì xã hội, xã hội vừa là khách thể nghiên cứu song đồng thời cũng là mục tiêu, động lực để thúc đẩy các ngành khoa học này phát triển, quan tâm nghiên cứu để giải quyết chính các vấn đề của con người - xã hội đang ứng phó. Đó là phát hiện nhu cầu xã hội, điều kiện sống, thực trạng quan hệ xã hội của các giai cấp, tầng lớp, nhóm xã hội,.. và đề ra các biện pháp tác động đến những thực tế này. Từ đó có thể khẳng định, xã hội hoc nước ta thời kỳ này suy cho cùng là "góp phần giải quyết các vấn đề xã hội nảy sinh trên từng chặng đường công nghiệp hoá, hiện đại hoá, trên từng bước đi của thời kỳ quá độ lên chủ nghĩa xã hội" [12, tr.11]. Trong khi đó, khoa học chính sách xã hội như đã từng đề cập, đó là xem xét sự tác động của chính sách xã hội thế nào đến con người và xã hội đương đại đồng thời, con người và xã hội ấy tác động ngược chính sách xã hội ra sao [10, tr.40-41] dưới lăng kính khoa học. Thực chất, suy cho cùng, trung tâm của vấn đề cơ bản có tính triết học trong khoa học chính sách công cũng là phục vụ giải quyết vấn đề thuộc về xã hội và con người trong xã hội ấy. Như vậy, từ bản chất, mục tiêu của mình, hai ngành khoa học này có quan hệ biện chứng rất chặt chẽ. 
Ba là, thông qua phương diện là công cu và phương pháp nghiên cứu. Không thể phủ nhận mỗi ngành đều có phương pháp nghiên cứu đặc thù. Đối với xã hội học là phương pháp nghiền cứu xã hội thực nghiệm thông qua quan sát, so sánh, điều tra xã hội học, phòng vấn, phân tích lịch sử,...[13, tr.11]. Trong khi đó, khoa học chính sách xã hội chú ý sử dụng phương pháp nghiên cứu trường hợp, phân tích chính sách, nghiên cứu lịch sử cộng đồng và một phần phương pháp nghiên cứu định lượng,.... Tuy nhiên, trong bối cảnh việc áp dụng các phương pháp nghiên cứu "xuyên ngành" và thực tiễn ngày càng có nhiều công trình khoa học về chính sách công, chính sách xã hội, giới nghiên cứu về khoa học chính sách xã hội áp dụng một cách thuần thục, phổ biến và phát huy hiệu quả phương pháp nghiên cứu xã hội học đã tạo nên sự tươi mới, thực chứng và hàm lượng khoa học cao trong nghiên cứu về các vấn đề xã hội đương đại $[11, \text { tr.45 }]^{1}$. Như vậy, xã hội học đã cung cấp hệ thống phương pháp nghiên cứu giúp bổ sung cho các phương pháp của khoa học chính sách xã hội nhằm thích ứng yêu cầu trong nghiên cứu và đòi hỏi của xã hội ngày nay.

Bốn là, thông qua phưong diện là hệ thống lý thuyết xã họi học. Có thể khẳng định, hệ thống lý thuyết khổng lồ, đồ sộ của xã hội học là sản phẩm trí tuệ của các nhà xã hội học vĩ đại thế kỷ XIX và những người kế tục sự nghiệp ấy. Hệ thống lý thuyết ấy là sự nghiền ngẫm, nghiên cứu bởi "những con người khổng lổ biết phát hiện vấn đề và đưa ra câu trả lời cho những câu hỏi lớn của thời đại” [1] như F. Ăngghen từng nhận xét, là sự tự vấn và tìm ra lời giải đáp có tính quy luật phổ quát, trừu tượng hoá, khái quát hoá từ các hiện tượng, sự kiện, vấn đề xã hội đâu đó, của nhóm cộng đồng, quốc gia tưởng chừng có tình rời rạc; đồng thời giúp nhận loại nhận thức của bản chất, vấn đề có tính chất triết học của xã hội đương đại không thể xa rời mối quan hê giữa con người và xã hội. Hệ thống các lý thuyết ấy có thể kể đến như lí thuyết chức năng của Talcott

\footnotetext{
${ }^{1}$ Trong một nghiên cứu cách đây hơn 30 năm, GS Bùi Thế Cường đã khẳng định: "Khi hướng đến một lĩnh vực cụ thể nào đó, nghiên cứu chính sách xã hội khồng thể không sử dụng kết quả cũng như phương pháp của những bộ môn
}

Parason và Robert Merton, lí thuyết mâu thuẫn của Wright Mills, Ralf Dahrendorf, lí thuyết lựa chọn hợp lí của Geogre Homans, Peter Blau, lí thuyết về phân tầng xã hội; hành động xã hội và tổ chức xã hội của Max Weber,... Thực tế cho thấy rằng, các nghiên cứu về khoa học chính sách xã hội hiện nay đang yếu, thiếu và loay hoay tìm kiếm một "điểm tựa" lý thuyết để luận giải về cái mà nghiên cứu gọi là "thực trạng", là "vấn đề chính sách xã hội", là cái tồn tại hay khiếm khuyết trên nền tảng khoa học có trường phái và có tính thuyết phục cao. Và ở đó, không tuyệt đối song gần như các lý thuyết xã hội học đã mang đến "điểm tựa chân lý" có sức thuyết phục cao để các nhà khoa học về chính sách xã hội mạnh dạn hơn trong luận giải các hiện tượng, vấn đề mà nghiên cứu của mình đặt ra. Tất nhiên, điều này cũng không đồng nghĩa khoa học chính sách xã hội đang trở nên bị động. Kết quả nghiên cứu của khoa học chính sách mang đến căn cứ thực tiễn thuyết phục hơn hết để từng bước bổ sung, chứng minh, hoặc bác bỏ hoăc làm rõ nội hàm các lý thuyết mà các nhà xã hội học đã dày công nghiên cứu. Đó là quan hệ biện chứng ở phương diện lý thuyết xã hội học trong nghiên cứu khoa học chính sách xã hội.

\section{4. Ý nghĩa khoa học và một số vấn đề đặt ra trong nghiên cứu chính sách xã hội qua cách tiếp cận xã hội học}

Qua các phân tích và luận bàn trên, có thể thấy, việc tiếp cận nghiên cứu khoa học chính sách xã hội qua lăng kính xã hội học ở nước ta hiện nay đang đặt ra một số vấn đề cần suy ngẫm như sau:

Một là, nghiên cứu khoa học chính sách xã hội từ cách tiếp cận của xã hội học đã đưa hai ngành khoa học vốn còn non trẻ này trở nên "gần nhau" hơn ở góc nhìn khoa học và thực tiễn. Điều này góp phần thay đổi tích cực nhận thức của xã hội về chủ đề này nhất là với các ý kiến

khoa học liên quan đến lĩnh vực ấy (trong đó bao hàm cả kinh tế học, xã hội học, y học, giáo dục học, lão học,...) (Trích: Bùi Thế Cường (1986), "Xã hội học và chính sách xã hội”, Tạp chí Xã hội học, số 4-1986, tr. 45) 
trái chiều, phản bác gay gắt hoặc suy nghĩ chưa tận tường khi cho rằng chúng là hai lĩnh vực, hai ngành khoa học hoàn toàn độc lập, không gì liên hệ nhau. Đặc biệt, với cách tiếp cận này, việc hình thành một bộ môn khoa học, ngành khoa học mới "xã hội học chính sách", "xã hội học chính sách xã hội",... là một ý tưởng không phải quá viễn vong từ thực tiễn của Việt Nam hiện nay.

Hai là, nghiên cứu khoa học chính sách xã hội qua cách tiếp cận xã hội học giúp chính sách xã hội học có công cụ, phương thức nghiên cứu, giải quyết đối với các vấn đề của chính sách xã hội một cách thấu triệt, toàn diện, tận cùng, hiện đại, khắc phục tính non trẻ, mới mẻ của ngành khoa học này ở Việt Nam thời gian qua. $\mathrm{F}$. Ăngghen từng nhấn mạnh, cảnh báo đối với tất cả ngành khoa học cách đây hơn một thế kỷ, trong đó, cũng là bài học trong nghiên cứu khoa học chính sách xã hội rằng "sư khinh thường lý luận là con đường chắc chắn đưa chúng ta đến chỗ suy nghĩ theo lối tự nhiên chủ nghĩa, tức là suy nghĩ sai” [2]. Nếu nghiên cứu khoa học chính sách xã hội thiếu đi phương pháp thực nghiệm, có tính thực chứng cao, hiện đại sẽ dẫn đến hiệu quả, hiệu lực không cao và tác động tiêu cực của hệ thống chính sách xã hội được xây dựng và ban hành đển đời sống nhân dân. Do vậy, cách tiếp cận khoa học xã hội học từ lăng kính xã hội học, đặc biệt ở phương diện mục tiêu, phương pháp nghiên cứu sẽ giúp cải biến nhận thức của các chính trị gia, các nhà quản lý và đội ngũ xây dựng chính sách quốc gia nói chung, trong đó, có chính sách xã hội bởi sự "dè dặt" hoặc chưa coi trọng hoặc chưa áp dụng mạnh mẽ, xác đáng các ưu điểm của xã hội học trong nghiên cứu và xây dựng hệ thống chính sách xã hội cho đất nước.

Ba là, hướng nghiên cứu khoa học chính sách xã hội của bài viết này giúp xã hội học thực thi được tính "xã hội”, trở về "xã hội” vốn có của ngành khoa học này. Sản phẩm của xã hội học được đúc kết bởi các lý thuyết đồ sộ, đa dạng trên nhiều phương diện của đời sống xã hội, là các quy luật được trừu tượng hoá về mối quan hệ giữa con người với xã hội và ngược lại. Tuy vậy, thông qua khoa học chính sách xã hội, các lí thuyết, quy luật này có cơ hội được trở lại phục vụ, lí giải, bổ sung cho các vấn đề xuất phát từ thực tiễn, được áp dụng để luận giải và mang lại sự hữu ích cho cộng đồng xã hội, quốc gia bởi hệ thống chính sách xã hội được thực thi; đồng thời, từ thực tiễn mà các lý thuyết này ngày càng được bổ sung và hoàn thiện.

Bốn là, nghiên cứu khoa học xã hội qua cách tiếp cận xã hội học trong thời gian tới đang đứng trước một số thách thức như sau:

(1). Việc chưa "toàn vẹn" hay thậm chí có độ "trễ" về mặt lịch sử của hệ thống lý thuyết xã hội học là điều cần chú ý trong việc áp dụng chúng trong nghiên cứu khoa học chính sách xã hội. Điều này tuy tạo ra thách thức song cũng đồng thời tạo nên thái độ áp dụng lý thuyết xã hội trong nghiên cứu chính sách xã hội có chủ đích hơn, không ngừng hoàn thiện, bồ sung các lý thuyết hiện có và phát kiến các lý thuyết mới qua các công trình nghiên cứu khoa học chính sách xã hội.

(2). Phát huy đặc tính là ngành khoa học liên ngành trong nghiên cứu khoa học chính sách xã hội ngay cả khi tiếp cận ở lăng kính xã hội học. T. Parason từng cảnh báo: “đừng nên nghiên cứu xã hội học bằng đôi tay trên của người thợ thủ công mà phải xây dựng xã hội học như một ngành khoa học thực thụ với hệ thống lý luận và phương pháp luận của nó" [14, tr.11]. Điều này có nghĩa là, ngoài tri thức, phương pháp nghiên cứu của xã hội, để có thể nghiên cứu chính sách xã hội học hiệu quả cần chú ý kết hợp, vận dụng lí thuyết và bổ sung nhận phương pháp luận của các ngành khoa học khác có liên quan mật thiết như tâm lý học, quản lý học, chính trị học, luật học,,.. để giải quyết tận cùng vấn đề của chính sách xã hội ở nước ta thời gian tới.

\section{Kết luận}

Nghiên cứu khoa học xã hội bằng lăng kính của xã hội học là cách tiếp cận mới, cần thiết nhằm gia tăng hàm lượng khoa học và tính hiệu lực, hiệu quả của hệ thống chính sách xã hội ở nước ta hiện nay. Bài viết là sự luận bàn về mối quan hệ biện chứng giữa xã hội học và khoa học chính sách xã hội trên 4 phương diện chủ yếu; qua đó cải biến nhận thức xã hội về vị trí, vai trò 
và tính tương tác lẫn nhau của hai ngành khoa học vốn còn non trẻ này; góp phần hình thành nền khoa học chính sách xã hội thực thụ, cung cấp tri thức và phương tiện hữu hiệu giúp các nhà chính sách cải tiến quá trình hoạch định, thực thi và đánh giá về hệ thống chính sách xã hội Việt Nam một cách chuyên nghiệp, hiện đại, hướng đến xây dựng xã hội phát triển hài hoá và tốt đẹp.

\section{Tài liệu tham khảo}

[1] Le Ngoc Hung: History and Sociological Theory, Social Sciences Publishing House, Hanoi, 2008 (In Vietnamese)

[2] Tran Minh Chien: Dessertation "The development of sociology in Vietnam" (through the study of articles learned in the Journal of Sociology from 1982 to 2008), defended at the National Academy of Politics and Public Administration Ho Chi Minh City, Hanoi, 2011 (In Vietnamese).

[3] Harold D. Lasswell: The Policy Orientation, The Policy Science:Recent Development in Scope and Method, Standford University Press, 1951.

[4] Anthony Giddens: Social theory and Modern Sociology, Polity Cambridge Press, 1987.

[5] V.Z. Rogovin: Social policies in developed socialist societies, Publishing House. Naura Moscow, 1980 (In Vietnamese).
[6] Nguyen Huu Hai: Public policy - Some basic issues, National Political - Truth Publishing House, Hanoi, 2014 (In Vietnamese).

[7] M.M. Rodentan, Dictionary of Philosophy, Publisher. Progress and Publisher, The truth, printed in the former Soviet Union, 1986 (In Vietnamese).

[8] Scott, John, Gordon Marshall (Eds.), A dictionary of Sociology, $3^{\text {rd }}$ edition revised, Oxford, Oxford University Press, 2009.

[9] Bui Dinh Thanh: Sociology and Social Policy, Social Sciences Publishing House, Hanoi, 2004 (In Vietnamese).

[10] Le Ngoc Hung, Characteristics of social policy science, Vietnam Journal of Social Sciences 10 (107) (2016) 40 - 41 (In Vietnamese).

[11] Bui The Cuong, Sociology and Social Policy, Journal of Sociology, 4 (1986) 45 (In Vietnamese).

[12] Trinh Duy Luan, Vietnamese Sociology: Some orientations for further construction and development, Journal of Sociology, 1 (2001) 11 (In Vietnamese)

[13] Pham Tat Dong, Le Ngoc Hung, Sociology, National University Publishing House, Hanoi, 2010 (In Vietnamese).

[14] Hermann Korte, Introduction to Sociological History, World Publishing House, Hanoi, 1997 (In Vietnamese). 